\title{
Kinetic activity of the sex chromosomes of Mormidea paupercula (Heteroptera: Pentatomidae)
}

\author{
Pablo Javier REBAGLiATI ${ }^{1}$ and Liliana María MOLA ${ }^{1,2}$
}

\author{
${ }^{1}$ Laboratorio de Citogenética y Evolución, Departamento de Ecología Genética y Evolución, Facultad de Ciencias Exactas y \\ Naturales, Universidad de Buenos Aires, Intendente Güiraldes y Costanera Norte, 1428 Ciudad Universitaria, Ciudad Autónoma de \\ Buenos Aires, Argentina; e-mails: gchu@ege.fcen.uba.ar, limola@ege.fcen.uba.ar \\ ${ }^{2}$ Investigador del Consejo Nacional de Investigaciones Científicas y Tecnológicas (CONICET)
}

Key words. Heteroptera, Pentatomidae, sex chromosomes, kinetic activity, holokinetic chromosomes, meiosis, Mormidea

\begin{abstract}
In Mormidea paupercula ( $\mathrm{n}=6+\mathrm{XY}$ in males), the presence of a $\mathrm{CMA}_{3}$-bright band in the telomeric regions on both sex chromosomes allowed the analysis of the kinetic activity of the sex univalents and XY pseudobivalent at the first and second meiotic divisions, respectively. The separation of the sister chromatids of the sex chromosomes occurs from a pair of telomeric regions (with or without a band), with opposite telomeric regions remaining associated with each other at meiosis I; the behaviour of both sex chromosomes differs, on the $\mathrm{X}$ chromosome both telomeric regions are similarly active, while on the $\mathrm{Y}$ chromosome the telomeric region without a band is more frequently active. At the second division, the most frequent associations in the pseudobivalent occur between the telomeric regions of both sex chromosomes with bands or without bands. Therefore, in both meiotic divisions, the same telomeric region on the sex chromosomes could lead the migration, in contrast to that observed usually in autosomal bivalents. These results provide evidence that the sex chromosomes of Heteroptera show more than one pattern of attachment to the spindle.
\end{abstract}

\section{INTRODUCTION}

A distinctive trait of the suborder Heteroptera is the presence of holokinetic chromosomes, i.e., with nonlocalised centromeres, as opposed to monocentric chromosomes, which are found in most organisms (Ueshima, 1979). In mitosis, microtubules are attached to nearly the entire length of the chromatid, while in chiasmatic meiosis the kinetic activity is restricted to the telomeric regions, and for this reason they are also known as telokinetic chromosomes (Buck, 1967; Comings \& Okada, 1972; Ueshima, 1979; González-García et al., 1996a; Mola \& Papeschi, 2006; Viera et al., 2009a).

The term reductional division refers to the separation of homologous segments at anaphase, while equational division implies the separation of sister segments at this stage. Two types of meiosis are described based on the sequence of these divisions and behaviour of the chromosomes. In the pre-reductional type the reductional division occurs during the first meiotic division and in the postreductional type it is delayed to the second meiotic division (Battaglia \& Boyes, 1955).

The autosomes and sex chromosomes of most Heteroptera exhibit different types of meiosis; the autosomal bivalents usually have a terminal chiasma, are oriented with their long axes parallel to the polar axis at metaphase I, and divide reductionally at the first meiotic division and equationally at the second division. Whereas, the sex chromosomes are achiasmatic, behave as univalents and divide equationally at the first meiotic division, while the $\mathrm{X}$ and $\mathrm{Y}$ chromosomes show the so-called touch-and-go pairing at the second meiotic division, forming a pseudobivalent, which divides reductionally (Ueshima, 1979).
Summarising, the autosomes undergo a pre-reductional meiosis while the sex chromosomes a post-reductional meiosis, which is designated inverted meiosis (reviewed by Viera et al., 2009a).

The analysis of behaviour of autosomal bivalents using chromosome markers (e.g., presence of C-bands, fluorescent bands, nucleolar organiser regions (NORs), or a terminal satellite in a single telomeric region) revealed that the pair of telomeric regions that are kinetically activity at the first meiotic division are inactive at the second division (Nokkala, 1985; Pérez et al., 1997; Cattani et al., 2004). However, kinetic activity in the same telomeric region occurs during the two meiotic divisions in a low percentage of cells (8.5\%) in Triatoma infestans (Klug, 1834) (Reduviidae) (Pérez et al., 2000). In addition, Camacho et al. (1985), who analysed the behaviour of the large chromosome pair in Nezara viridula (Linnaeus, 1758) (Pentatomidae), suggest that the kinetic activity of the telomeric regions at both meiotic divisions is not linked.

Chromosome markers are used less frequently to study the behaviour of sex chromosomes. González-García et al. (1996b) and Pérez et al. (2000), who analysed the kinetic behaviour of the X chromosome of Graphosoma italicum Muller, 1766 (Pentatomidae) and T. infestans, conclude that at metaphase I the two telomeric regions of each chromatid show kinetic activity and that the selection of the kinetically active telomeric region is independent between sister chromatids.

In Pentatomidae, the female chromosome complement of only 17 species is recorded, with sex chromosomes of equal size or with the X-chromosome larger than the Y-chromosome (Wilson, 1906, 1909, 1911; Schrader, 


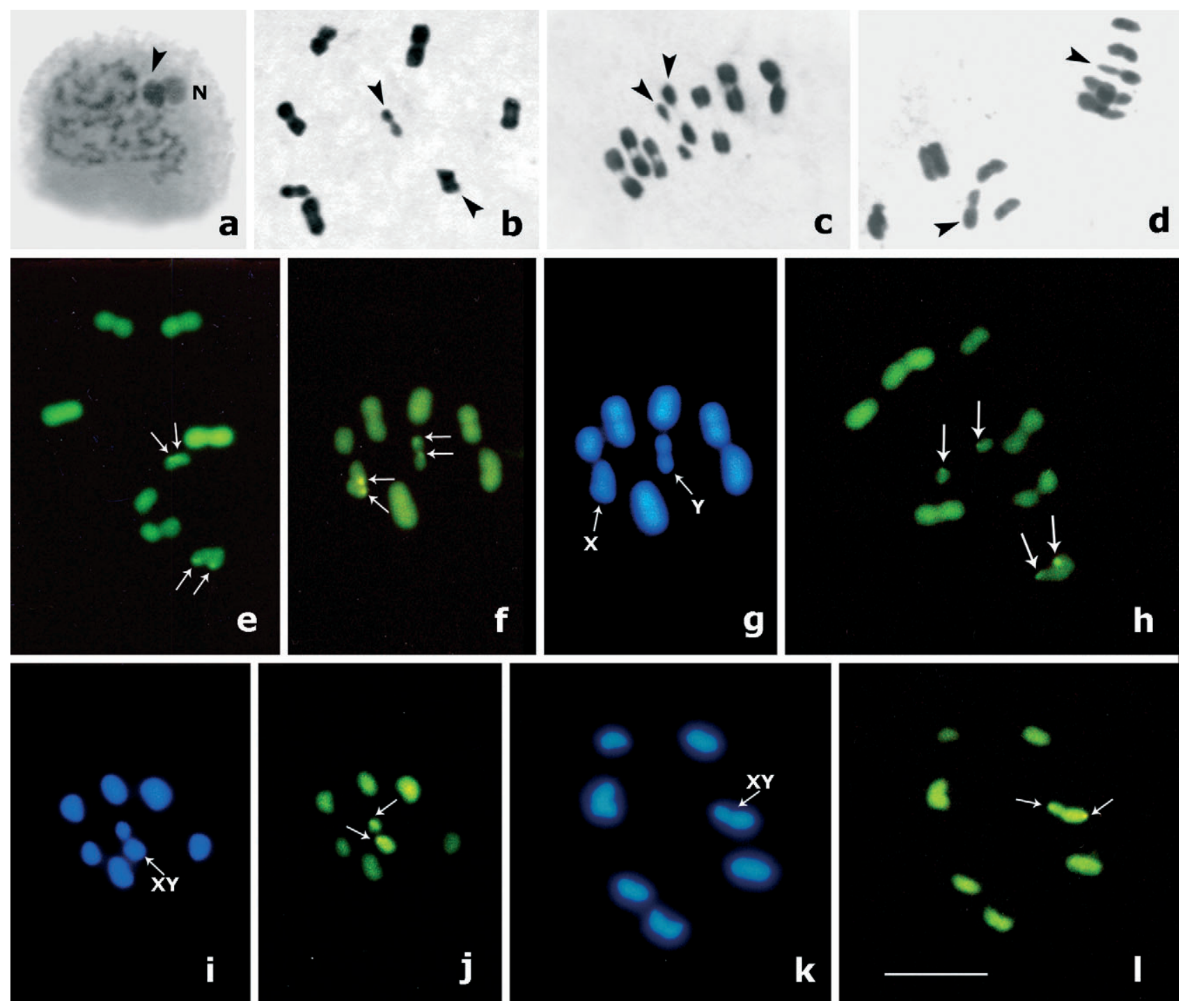

Fig. 1. Meiotic chromosomes of Mormidea paupercula males stained with hematoxylin (a-d), $\mathrm{CMA}_{3}(\mathrm{e}, \mathrm{f}, \mathrm{h}, \mathrm{j}, \mathrm{l})$, and DAPI (g, i, k). Pachytene (a); metaphase I (b, e-h); early anaphase I (c); metaphase II (d, i-l). Arrowheads point to sex chromosomes. Arrows point to $\mathrm{CMA}_{3}$ bands on the sex chromosomes. $\mathrm{N}$ - nucleolus. Bar $=10 \mu \mathrm{m}$.

1940, 1945a, b; Heizer, 1950; Schrader \& HughesSchrader, 1956, 1958; Srivastava, 1957). On this basis, the convention adopted in this study is that the larger chromosome is the $\mathrm{X}$ chromosome and the smaller the $\mathrm{Y}$ chromosome.

The present study analyses the meiotic behaviour of the sex chromosomes of Mormidea paupercula Berg, 1879 (Pentatomidae). $\mathrm{CMA}_{3}$-bright bands present in one of the telomeric regions of both the $\mathrm{X}$ and $\mathrm{Y}$ chromosomes are used as chromosome markers in a detailed analysis of their kinetic activity and that of the XY pseudobivalent at the first and second meiotic divisions, respectively.

\section{MATERIAL AND METHODS}

Adult males of Mormidea paupercula were collected from natural populations at Gualeguaychú, Entre Ríos Province, Argentina. The specimens were fixed in $3: 1$ absolute ethanol : glacial acetic acid; then, gonads were removed and stored in $70 \%$ ethanol at $4^{\circ} \mathrm{C}$. For meiotic studies, staining and squashing of a piece of gonad were done in $2 \%$ propionic haematoxylin in $45 \%$ propionic acid, using ferric citrate as a mordant.

Fluorescent staining with the $\mathrm{GC}$ specific $\mathrm{CMA}_{3}$ (chromomycin $\mathrm{A}_{3}$ ) and AT specific DAPI (4'-6-diamidino-2phenylindole) was carried out on unstained slides. A piece of gonad was squashed in $45 \%$ acetic acid; the coverslip was then removed by the dry-ice method and the slide air-dried. The sequential DAPI-CMA 3 banding of 13 males was determined using the technique described by Rebagliati et al. (2003).

\section{RESULTS AND DISCUSSION}

The male chromosome complement of Mormidea paupercula is composed of six pairs of autosomes and two sex chromosomes, $\mathrm{X}$ and $\mathrm{Y}$. At prophase I up to diplotene, the sex univalents are positively heteropycnotic and often found together and associated with the nucleolus (Fig. 1a). The bivalents have a terminal chiasma, with the larger bivalent occasionally having two chiasmata; the sex chromosomes differ in size, the $\mathrm{X}$ chromosome being about the size of the smaller bivalent 
and the $\mathrm{Y}$ chromosome about half the size of the $\mathrm{X}$ chromosome (Fig. 1b-d).

At metaphase I, the autosomal bivalents are arranged in a ring-shaped figure in the equatorial plane, while the sex chromosomes are usually part of the ring or the $\mathrm{Y}$ chromosome lies at its centre (Fig. 1b, e-h). At this stage, the chromatids of the $\mathrm{X}$ chromosome align side-by-side (Fig. 1b), but at late metaphase I they separate and take up a position perpendicular to the equatorial plane. At the first meiotic division, the autosomes segregate reductionally and the sex chromosomes equationally (Fig. 1c). At metaphase II, the XY pseudobivalent lies at the centre of the autosomal ring and segregates reductionally at anaphase II (Fig. 1d).

In $M$. paupercula the autosomal bivalents exhibited homogeneous DAPI-CMA $\mathrm{C}_{3}$ staining at all meiotic stages, whereas the sex chromosomes were DAPI-bright and showed $\mathrm{CMA}_{3}$-bright bands in one of their telomeric regions. In Hemiptera, the NORs are usually associated with $\mathrm{CMA}_{3}$-bright bands, indicating that they are GC-rich (Mola \& Papeschi, 2006; Criniti et al., 2009). Given the association between the sex chromosomes and the nucleolus in $M$. paupercula it is likely that the $\mathrm{CMA}_{3}$ bright bands contain ribosomal DNA (rDNA). In regard to the effects of rDNA genes on chromosome pairing and segregation, the NORs and particularly the 240-bp repeats of the intergenic spacer are reported to function as pairing sites of the sex chromosomes in many species of Drosophila (Roy et al., 2005). In aphids, in parthenogenetic females during mitosis and in parthenogenetic eggs both $\mathrm{X}$ chromosomes are associated by their NORs. In eggs developing into males this connection has an effect on segregation and the $\mathrm{X}$ chromosomes undergo a particular division resulting in eggs with a single $\mathrm{X}$ chromosome (Mandrioli et al., 1999; Criniti et al., 2009). Mandrioli et al. (1999) state that the rDNA arrays and nucleolar material could be involved in the regulation of the association of the sex chromosomes in mitosis and meiosis of different animal phyla.

González-García et al. (1996b), Pérez et al. (2000) and Viera et al. (2009a) propose that at metaphase I, the sideby-side association of the chromatids of the sex chromosomes and their orientation (the long axis is parallel to the equatorial plate) should be frequent in Heteroptera. However, these authors point out that it is observed only if the chromosomes carry a marker. In addition, they suggest that (1) the spindle fibres interact with the chromatids of the $\mathrm{X}$ chromosome along their entire length to stabilize it on the metaphase plate, (2) at late metaphase I the sex chromatids segregate and the kinetic activity is restricted to the telomeric regions.

In M. paupercula, as in G. italicum and T. infestans, at metaphase I the chromatids of the $\mathrm{X}$ chromosome are parallel and segregation is deferred until late metaphase I. In contrast, the chromatids of the $\mathrm{Y}$ chromosome are separate and perpendicular to the equatorial plane throughout metaphase I. This difference in the arrangement of the sister chromatids between sex chromosomes may be related to the disassembly of cohesin complexes that hold
METAPHASE I
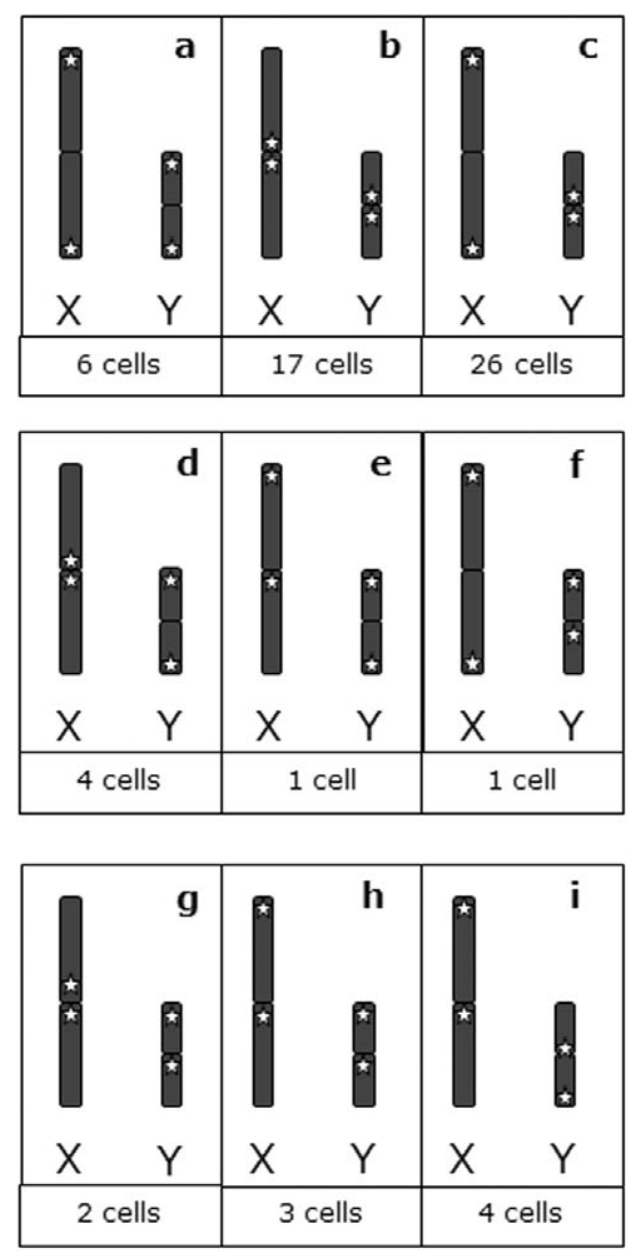

METAPHASE II

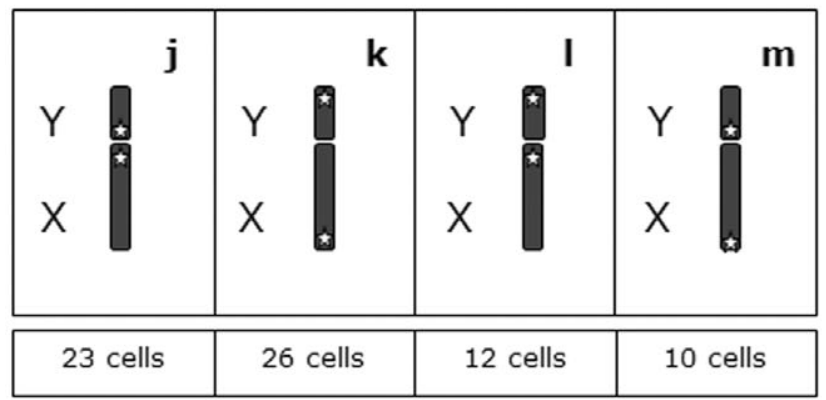

Fig. 2. Diagram showing location of $\mathrm{CMA}_{3}$-bright bands on sex chromosomes of Mormidea paupercula spermatocytes at metaphase I ( $\mathrm{a}-\mathrm{i})$ and metaphase II $(\mathrm{j}-\mathrm{m})$.

them together (Viera et al., 2009b). Given the small size of the Y chromosome, these complexes could be completely disassembled early in metaphase I.

The $\mathrm{CMA}_{3}$-bright bands on both sex chromosomes allowed us to analyse the kinetic behaviour of the $\mathrm{X}$ and $\mathrm{Y}$ chromatids in the two meiotic divisions.

At metaphase I, the chromatids of both $\mathrm{X}$ and $\mathrm{Y}$ chromosomes can separate in any of three patterns, dependent on which telomeric region is driving the movement, i.e. the banded (b) or the non-banded one (nb): (i) both 
TABLE 1. Results of the statistical analysis of the behaviour of the sex chromosomes of Mormidea paupercula at the first and second meiotic divisions. NSD, non-significant difference $(P>0.05)$.

$\mathrm{A}$ - Analysis of the active telomeric regions on the $\mathrm{X}$ and $\mathrm{Y}$ chromosomes at the first meiotic division assuming chromatid random kinetic activity.

\begin{tabular}{|c|c|c|c|c|}
\hline Active telomeric region & Number of cells examined & $\chi^{2}$ & Degrees of freedom & Statistical significance \\
\hline $\mathrm{X}$ b...nb-nb...b & 33 & \multirow{3}{*}{39.125} & \multirow{3}{*}{2} & \multirow{3}{*}{$P<0.001$} \\
\hline nb...b-b...nb & 23 & & & \\
\hline b...nb-b...nb & 8 & & & \\
\hline Y b...nb-nb...b & 11 & \multirow{3}{*}{62.25} & \multirow{3}{*}{2} & \multirow{3}{*}{$P<0.001$} \\
\hline nb...b-b...nb & 43 & & & \\
\hline b...nb-b...nb & 10 & & & \\
\hline
\end{tabular}

$\mathrm{B}$ - Analysis of the active telomeric regions on the $\mathrm{X}$ and $\mathrm{Y}$ chromosomes at the first meiotic division assuming they are equally likely to be kinetically active.

\begin{tabular}{lcccc}
\hline Active telomeric region & Number of cells examined & $\chi^{2}$ & Degrees of freedom & Statistical significance \\
\hline $\mathrm{b} \mathrm{X}$ & 33 & 0.893 & 1 & NSD \\
$\mathrm{nb} \mathrm{X}$ & 23 & & 1 & $P<0.001$ \\
$\mathrm{~b} \mathrm{Y}$ & 11 & 13.96 & 1 & \\
$\mathrm{nb} \mathrm{Y}$ & 43 & & & \\
\hline
\end{tabular}

$\mathrm{C}$ - Analysis of the active telomeric regions on the $\mathrm{X}$ and $\mathrm{Y}$ chromosomes at the second meiotic division.

\begin{tabular}{lcccc}
\hline Active telomeric region & Number of cells examined & $\chi^{2}$ & Degrees of freedom & Statistical significance \\
\hline $\mathrm{b} \mathrm{X}$ & 36 & 0.014 & 1 & NSD \\
$\mathrm{nb} \mathrm{X}$ & 35 & & 1 & NSD \\
$\mathrm{b} \mathrm{Y}$ & 38 & 0.352 & 1 & \\
$\mathrm{nb} \mathrm{Y}$ & 33 & & & \\
\hline
\end{tabular}

$\mathrm{D}$ - Analysis of the active telomeric regions of the $\mathrm{XY}$ pseudobivalent assuming random association.

\begin{tabular}{lccc}
\hline & b X & nb X & Total \\
\hline b Y & 26 & 12 & 38 \\
nb Y & 10 & 23 & 33 \\
Total & 36 & 35 & 71 \\
\hline
\end{tabular}

$\chi^{2}=10.27 \mathrm{df}=1 \ldots P=0.014$

$\mathrm{E}$ - Analysis of the Y chromosome active telomeric region in the XY pseudobivalent assuming the alternate hypothesis.

\begin{tabular}{lcccc}
\hline Active telomeric region & Number of cells examined & $\chi^{2}$ & Degrees of freedom & Statistical significance \\
$\mathrm{nb}$ Y & 33 & 29.84 & 1 & $P<0.001$ \\
$\mathrm{~b} \mathrm{Y}$ & 38 & & & $P$ \\
\hline
\end{tabular}

$\mathrm{F}$ - Analysis of the $\mathrm{Y}$ chromosome active telomeric region in the $\mathrm{XY}$ pseudobivalent assuming the precondition hypothesis.

\begin{tabular}{lcccc}
\hline Active telomeric region & Number of cells examined & $\chi^{2}$ & Degrees of freedom & Statistical significance \\
$\mathrm{nb} \mathrm{Y}$ & 33 & 48.10 & 1 & $P<0.001$ \\
$\mathrm{~b} \mathrm{Y}$ & 38 & & & \\
\hline
\end{tabular}

banded telomeric regions show kinetic activity (b...nb-nb...b), (ii) both non-banded telomeric regions show kinetic activity (nb...b-b...nb) and (iii) one banded and one non-banded telomeric regions show kinetic activity (b...nb-b...nb or vice versa). In the case of random kinetic activity of both telomeric regions on both chromatids, the third configuration is twice as likely to occur as the other two (1:1:2, respectively). Studies on the $\mathrm{X}$ chromosome of $G$. italicum and $T$. infestans reveal the behaviour of the chromatids of the $\mathrm{X}$ chromosome relative to one another is random, which indicates they are attached to the spindle fibres independently of each other (González-García et al., 1996b; Pérez et al., 2000).
In Mormidea paupercula, the kinetic activity of the $\mathrm{X}$ and $\mathrm{Y}$ chromosomes was analysed at late metaphase I, when their sister chromatids separate (Fig. 1e-h; Fig. $2 \mathrm{a}-\mathrm{i}$ ). Nine different combinations of the $\mathrm{X}$ and $\mathrm{Y}$ chromosomes were observed based on the location of the $\mathrm{CMA}_{3}$-bright bands; the different arrangements of the bands and the number of cells with each band arrangement are detailed in Fig. $2 \mathrm{a}-\mathrm{i}$. When results of the $\mathrm{X}$ and $\mathrm{Y}$ chromosomes were analysed, assuming random chromatid kinetic activity, significant differences between the expected and observed values were obtained for both sex chromosomes $(P<0.001)$ (Table 1A). Thus, the kinetic 
TABLE 2. Percentage of sex chromatid arrangements at the first meiotic division of Mormidea paupercula, Triatoma infestans, and Graphosoma italicum.

\begin{tabular}{|c|c|c|c|c|}
\hline \multirow[b]{2}{*}{ Species } & \multicolumn{3}{|c|}{$\dot{*}$ Marked telomeric region } & \multirow[b]{2}{*}{ References } \\
\hline & * & * & $\star$ & \\
\hline \multicolumn{5}{|c|}{ Mormidea paupercula } \\
\hline $\mathrm{X}$ chromosome & 37.10 & 53.22 & 9.68 & \multirow{2}{*}{ This study } \\
\hline Y chromosome & 69.36 & 17.74 & 12.90 & \\
\hline \multicolumn{5}{|l|}{ Triatoma infestans } \\
\hline $\mathrm{X}$ chromosome & 24.50 & 28.30 & 47.20 & Pérez et al. (2000) \\
\hline \multicolumn{5}{|c|}{ Graphosoma italicum } \\
\hline $\mathrm{X}$ chromosome & 23.52 & 19.60 & 58.68 & González-García et al. (1996b) \\
\hline
\end{tabular}

activity of the telomeric regions on both sex chromosomes is not random.

In both sex chromosomes, the most frequent associations were between regions with or without bands (56 cells for the $\mathrm{X}$ chromosome and 54 for the $\mathrm{Y}$ chromosome, from a total of 64 cells) (Fig. 2a-g, Table 2).

As the same telomeric regions on the sex chromosomes associate more frequently at metaphase I and assuming that both telomeric regions have the same probability of showing kinetic activity, the distribution of the arrangements (i) and (ii) should be $1: 1$, for both the $\mathrm{X}$ and $\mathrm{Y}$ chromosomes. The deviation between the observed and the expected values was not statistically significant for the $\mathrm{X}$ chromosome, but significant for the $\mathrm{Y}$ chromosome $(P$ $<0.001)$; the probability of the region without a band leading the migration to the spindle pole was four times greater than the region with a band (Table 1B).

Taking into account the cohesin complex holding sister chromatids together (Page et al., 2006), it can be postulated that these separate gradually in the $\mathrm{X}$ chromosome, with the complex beginning to disassemble in the telomeric regions. This would contribute to a shift from a holokinetic interaction with the spindle fibres to an interaction restricted to the telomeric regions (GonzálezGarcía et al., 1996b; Viera et al., 2009a, b). In G. italicum and $T$. infestans this disassembly would begin simultaneously in both telomeric regions, allowing sister chromatids to undergo kinetic activity independently of one another (Viera et al., 2009a). Instead, in M. paupercula the disassembly seems to begin in only one of the telomeric regions, on the $\mathrm{Y}$ chromosome mainly in the nonbanded one or any telomeric region on the $\mathrm{X}$ chromosome.

The disposition of the sex chromosomes in the centre of the ring formed by autosomal bivalents in Oncopeltus fasciatus Dallas, 1852 (Lygaeidae) led Wolfe \& John (1965) to postulate that the chromatids of the $\mathrm{X}$ and $\mathrm{Y}$ chromosomes at anaphase I would be optimally placed to become attached by the active telomeric regions on the XY pseudobivalent, as a consequence of a lack of interkinesis. Based on this hypothesis, González-García et al. (1996b) suggest that the telomeric regions of the sex chromosomes that are kinetically active at the first meiotic division are inactive at the second because they are involved in the touch-and-go pairing, which keeps the pseudobiva- lent attached at metaphase II. The sex chromosomes of $M$. paupercula are differently arranged: they are part of the bivalent ring or the $\mathrm{Y}$ chromosome lies at its centre, migrating separately at anaphase I. This independent migration may lead to a random association of the $\mathrm{X}$ and $\mathrm{Y}$ chromosomes in the pseudobivalent.

At metaphase II, the $\mathrm{CMA}_{3}$-bright bands revealed the following four possible associations between the $\mathrm{X}$ and $\mathrm{Y}$ chromosomes in the pseudobivalent: association between telomeric regions with bands or without bands and association between the telomeric region with a band on one chromosome and the telomeric region without a band on another, and vice versa (Fig. $2 \mathrm{j}-\mathrm{m}$ ).

In considering the kinetic behaviour of the $\mathrm{X}$ and $\mathrm{Y}$ chromosomes regardless of their association in the pseudobivalent, any of the telomeric regions could randomly lead the migration at anaphase II $(1: 1$ distribution for each sex chromosome). No statistically significant deviation was found between observed and expected values for the $\mathrm{X}$ and $\mathrm{Y}$ chromosomes (Table 1C).

Since both telomeric regions of the $\mathrm{X}$ and $\mathrm{Y}$ chromosomes have the same probability of leading the migration in the second meiotic division, it can be assumed that there is a random association between the chromatids of the $\mathrm{X}$ and $\mathrm{Y}$ chromosomes in the pseudobivalent and the distribution of the different arrangements should be $1: 1$ : $1: 1$ (Fig. 2j-m). A significant deviation between the observed and expected values was found $(P<0.05)$ (Table 1D).

This result rejects the random hypothesis, and shows that, as at metaphase I, there is a preference for kinetic activity in similar banded or non-banded telomeric regions on both the $\mathrm{X}$ and $\mathrm{Y}$ chromosomes in the pseudobivalent (Table 1D). Given that the two telomeric regions on the $\mathrm{X}$ chromosome are equally likely to lead the migration at anaphase I, only the behaviour of the Y chromosome can provide information on the kinetically active telomeric region during the second division. Two hypotheses can be tested: the first hypothesis postulates that the Y chromosome alternates between meiotic divisions, with the distribution of banded and non-banded regions that lead the migration being $43: 11$, respectively. There was a significant deviation between the observed and expected values $(P<0.001)$ (Table $1 \mathrm{E})$. The second hypothesis is that kinetic activity at metaphase I pre- 
conditions kinetic activity in the same telomeric region at metaphase II, with the distribution of banded and nonbanded regions that lead the migration being $11: 43$, respectively. In this case a significant deviation between the observed and expected values was also observed $(P<$ 0.001) (Table 1F).

The combined results of these tests indicate that kinetic activity in the second meiotic division is independent of that in the first. This behaviour is completely consistent with that described by Camacho et al. (1985) for autosomal bivalents of Nezara viridula.

The autosomes and sex chromosomes of species with achiasmatic meiosis show a different kinetic behaviour; for example, the chromosomes of three species of Nabis migrate parallel to the equatorial plane in both meiotic divisions and show genuine holokinetic behaviour rather than telokinetic activity (Nokkala \& Nokkala, 1984). In the few species with this particular type of meiosis, the autosomes also divide pre-reductionally and the sex chromosomes post-reductionally (Nokkala \& Grozeva, 2000; Ituarte \& Papeschi, 2004).

\section{CONCLUDING REMARKS}

The selection of the kinetically active telomeric region is independent between sister chromatids of the $\mathrm{X}$ chromosome in Graphosoma italicum and Triatoma infestans. The present study indicates that in Mormidea paupercula the sister chromatids of the sex chromosomes do not behave independently of each other in their attachment to the spindle fibres at metaphase I. Rather, their separation occurs from the same telomeric regions (with or without $\mathrm{CMA}_{3}$-bright band) with the opposite telomeric regions remaining associated with each other in a large proportion of cells (Table 2). However, the sex chromosomes differed in their behaviour: on the X chromosome, the telomeric regions with and without a band were active to the same degree, while on the Y chromosome, the telomeric region without a band was more frequently active.

Moreover, the sex chromosomes do not associate randomly in the pseudobivalent, with the most frequent associations occurring between telomeric regions of both chromosomes with bands or without bands.

Therefore, the same telomeric region of the sex chromosomes could lead the migration in both meiotic divisions. In addition, the NORs in the telomeric regions of the sex chromosomes may not affect the association of chromatids. Although, in M. paupercula this association is likely to occur mainly between the chromatids of the $\mathrm{Y}$ chromosome; the chromatids of the $\mathrm{X}$ chromosome in this species and in G. italicum, and the association between both sex chromosomes in the pseudobivalent would not be affected by the presence of these highly repetitive regions.

This study, together with the findings discussed above provide evidence that the sex chromosomes of Heteroptera show more than one pattern of attachment to the spindle at meiosis, even within the same family, since $G$. italicum and M. paupercula both belong to the Pentatomidae.
The underlying reason for the difference in the selection of the active telomeric region at the first meiotic division between sex chromosomes, and the mechanisms involved in the pseudobivalent formation remain to be elucidated. Further studies using multiple chromosome markers are required to clarify the particular meiotic behaviour of the sex chromosomes of Heteroptera.

ACKNOWLEDGEMENTS. We would like to express our sincere gratitude to J.P.M. Camacho and an anonymous reviewer for their valuable suggestions for improving the final manuscript, and to J. Grazia (Universidade Federal do Rio Grande do Sul, Porto Alegre, Brazil) for her advice on the taxonomy of the specimens used in this study. The present study was funded grants from the Buenos Aires University (UBA) (X317, X178) and CONICET (PIP 5927, PIP 0342) to L. Poggio and L. Mola.

\section{REFERENCES}

Battaglia E. \& Boyes J.W. 1955: Post-reductional meiosis: its mechanism and causes. Caryologia 8: 86-134.

Buck R.C. 1967: Mitosis and meiosis in Rhodnius prolixus. The fine structure of the spindle and diffuse kinetochore. J. Ultrastruct. Res. 18: 489-501.

CAMAcho J.P.M., Belda J. \& CABRERo J. 1985: Meiotic behaviour of the holocentric chromosomes of Nezara viridula (Insecta, Heteroptera) analysed by C-banding and silver impregnation. Can. J. Genet. Cytol. 27: 490-497.

Cattani M.V., Greizerstein E.J. \& Papeschi A.G. 2004: Male meiotic behavior and nucleolus organizer regions in Camptischium clavipes (Fabr.) (Coreidae, Heteroptera) analyzed by fluorescent banding and in situ hybridization. Caryologia 57: 267-273.

Comings D.E. \& OKadA T.A. 1972: Holocentric chromosomes in Oncopeltus: kinetochore plates are present in mitosis but absent in meiosis. Chromosoma 37: 177-192.

Criniti A., Simonazzi G., Cassanelli S., Ferrari M., Bizzaro D. \& MANICARDI G.C. 2009: Distribution of heterochromatin and rDNA on the holocentric chromosomes of the aphids Dysaphis plantaginea and Melanaphis pyraria (Hemiptera: Aphididae). Eur. J. Entomol. 106: 153-157.

González-García J.M., Benavente R. \& Rufas J.S. 1996a: Cytochemical and immunochemical characterization kinetochores in the holocentric chromosomes of Graphosoma italicum. Eur. J. Cell Biol. 70: 352-360.

González-García J.M., Antonio C., Suja J.A. \& Rufas J.S. 1996b: Meiosis in holocentric chromosomes: kinetic activity is randomly restricted to the chromatid ends of sex univalents in Graphosoma italicum (Heteroptera). Chromosome Res. 4: 124-132.

Heizer P. 1950: The chromosome cytology of two species of the Pacific genus Oechalia (Pentatomidae, Hemiptera - Heteroptera) Oechalia patruelis Stal and Oechalia pacifica Stal. $J$. Morphol. 87: 179-226.

ItUarte S. \& Papeschi A.G. 2004: Achiasmatic male meiosis in Tenagobia (Fuscagobia) fuscata (Stal) (Heteroptera, Corixoidea, Micronectidae). Genetica 122: 199-206.

Mandrioli M., Bizzaro D., Giusi M., Manicardi G.C. \& BiANCHI U. 1999: The role of rDNA genes in X chromosome association in the aphid Acyrthosiphon pisum. Genome 42: 381-386.

Mola L.M. \& PAPeschi A.G. 2006: Holokinetic chromosomes at a glance. J. Basic Appl. Genet. 17: 17-33. 
NokKaLa S. 1985: Restriction of kinetic activity of holokinetic chromosomes in meiotic cells and its structural basis. Hereditas 102: 85-88.

NokKala S. \& Grozeva S.M. 2000: Achiasmatic male meiosis in Myrmnedonia coleoptrata (Fn.) (Heteroptera: Microphysidae). Caryologia 53: 5-8.

Nokkala S. \& Nokkala C. 1984: Achiasmatic male meiosis in the Heteropteran genus Nabis (Nabidae, Hemiptera). Hereditas 101: 31-35.

Page J., de la Fuente R., Gomez R., Calvente A., Viera A., Parra M.T., Santos J.L., Berríos S., Fernandez-Donoso R., Suja J.A. \& Rufas J. 2006: Sex chromosomes, synapsis, and cohesins: a complex affair. Chromosoma 115: 250-259.

Pérez R., Panzera F., Page J., Suja J.A. \& Rufas J.S. 1997: Meiotic behaviour of holocentric chromosomes: orientation and segregation of autosomes in Triatoma infestans (Heteroptera). Chromosome Res. 5: 47-56.

Pérez R., Rufas J.S., Suja J.A., Page J. \& Panzera F. 2000 Meiosis in holocentric chromosomes: orientation and segregation of an autosome and sex chromosomes in Triatoma infestans (Heteroptera). Chromosome Res. 8: 17-25.

Rebagliati P.J., Papeschi A.G. \& Mola L.M. 2003: Meiosis and fluorescent banding in Edessa meditabunda and Edessa rufomarginata (Heteroptera: Pentatomidae: Edessinae). Eur. J. Entomol. 100: 11-18.

Roy V., Monti-Dedieu L., Chaminade N., Siljak-Yakovlev S., Aulard S., Lemeunier F. \& Montchamp-Moreau C. 2005: Evolution of the chromosomal location of rDNA genes in two Drosophila species subgroups: ananassae and melanogaster. Heredity 94: 388-395.

SCHRAder F. 1940: The formation of tetrads and meiotic mitoses in the male of Rhytidolomia senilis Say (Hemiptera, Heteroptera). J. Morphol. 67: 123-141.

SCHRADER F. 1945a: Regular occurrence of heteroploidy in a group of Pentatomidae (Hemiptera). Biol. Bull. 88: 63-70.
Schrader F. 1945b: The cytology of regular heteroploidy in the genus Loxa (Pentatomidae - Hemiptera). J. Morphol. 76: 157-177.

Schrader F. \& Hughes-Schrader S. 1956: Polyploidy and fragmentation in the chromosomal evolution of various species of Thyanta (Hemiptera). Chromosoma 7: 469-497.

SCHRADER F. \& Hughes-Schrader S. 1958: Chromatid autonomy in Banasa (Hemiptera: Pentatomidae). Chromosoma 9: 193-215.

SRIVASTAVA M.D.L. 1957: Compound sex chromosome mechanism and regular occurring meiotic aberrations in the spermatogenesis of Macropygium reticulare (Pentatomidae - Heteroptera). Cellule 58: 252-274.

Ueshima N. 1979: Hemiptera II: Heteroptera. In John B. (ed.): Animal Cytogenetics. Vol. 3, Insecta 6. Gebrüder Bornträger Berlin, pp. 1-113.

Viera A., PAge J. \& Rufas J.S. 2009a: Inverted meiosis: The true bugs as a model to study. Genome Dyn. 5: 137-156.

Viera A., Santos J.L., Parra M.T., Calvente A., Gomez R., De la Fuente R., Suja J.A., Page J. \& Rufas J.S. 2009b: Cohesin axis maturation and presence of RAD51 during first meiotic prophase in a true bug. Chromosoma 118: 1-15.

WILSON E. 1906: Studies on chromosomes III. The sexual differences of the chromosome-groups in Hemiptera, with some considerations on the determination and inheritance of sex. $J$. Exp. Zool. 3: 1-40.

WILSON E. 1909: Studies on chromosomes IV. The accessory chromosome in Syromastes and Pyrrhocoris, with comparative review of the types of sexual difference of the chromosome groups. J. Exp. Zool. 6: 69-99.

WILson E. 1911: Studies on chromosomes VII. A review of the chromosomes of Nezara with some more general considerations. J. Morphol. 22: 71-110.

WoLfE S.L. \& JoHN B. 1965: The organization and ultrastructure of male meiotic chromosomes in Oncopeltus fasciatus. Chromosoma 17: 85-103.

Received October 30, 2009; revised and accepted March 26, 2010 